\title{
El lector como reparador de significado. Un ejemplo práctico de instrucción directa en estrategias metacognitivas
}

Recibido: febrero 2012

\author{
Andrés CALERO \\ Instituto Cañada Blanch (Londres) \\ acalero1@gmail.com
}

Aceptado: noviembre 2012

\section{RESUMEN}

La metáfora del lector como "reparador" de significado - creada desde el enfoque metacognitivo a partir de los trabajos de Flavell (1976) y Brown (1978) - identifica en el ámbito del desarrollo de la comprensión lectora al lector que se pretende conseguir en los centros escolares en la actualidad. Por un lado, el tipo de lector que se desea es el que es capaz de elaborar conocimiento sobre variables personales y de la tarea lectora; y por otro, es competente en el uso de estrategias lectoras y en el control y regulación del proceso de comprensión que sigue al leer.

Para conseguir este arquetipo de lector, es necesario que el profesorado de educación primaria y secundaria obligatoria equipe a sus alumnos con la correspondiente "caja de herramientas"; es decir, con aquellas estrategias o recursos metacognitivos que les ayuden a supervisar y controlar el significado que van construyendo, o a repararlo en el caso de que surja cualquier fallo en la comprensión. Esas herramientas no son otra cosa sino las estrategias metacognitivas, que juegan un importante papel como procesos de pensamiento asociados al desarrollo y al control de la comprensión lectora, tal como se indica en el Programa de la OCDE para la Evaluación Internacional de Alumnos PISA 2009.

Con estas premisas, en este artículo desarrollamos, paso a paso, la práctica de un ejemplo de enseñanza directa de la estrategia metacognitiva "clarificamos el significado", con actividades que ayudan a los lectores a descubrir y aprender a "reparar" la comprensión de palabras y partes del texto en las que el significado se ha visto afectado. Concluimos que una enseñanza directa y explícita de estrategias metacognitivas ayuda al estudiante a construir conocimiento, y crea conciencia metacognitiva en el proceso de control de la comprensión lectora (Calero, 2011).

La estrategia la hemos segmentado en cinco componentes, que representan "porciones de conocimiento metacognitivo" a ser controlados progresivamente por los estudiantes. La enseñanza de estos componentes conlleva tareas tales como el modelaje por parte del profesor, el trabajo en grupos y prácticas guiadas e independientes en tres fases: a) el docente introduce el significado de la estrategia y el uso de cada uno de sus componentes, a través de la actividad de reflexión en voz alta, b) la aplicación y utilización de los distintos componentes en actividades de pequeños grupos, con tareas de lecturas previamente seleccionadas, y c) la autoevaluación y el establecimientos de objetivos de mejora por parte del estudiante, advirtiendo en qué componentes de esta estrategia tiene éxito en su aplicación y en cuáles necesita mejorar para restablecer el significado perdido. 
Palabras clave: metacognición, lector como reparador de significado, estrategias metacognitivas, aprender a aprender, clarificación de significado, conciencia morfológica, relectura, control de la comprensión.

\title{
The Reader as a meaning fixer. A practical example of direct instruction in metacognitive strategies
}

\begin{abstract}
The metaphor of the reader as a meaning "fixer", developed by the metacognitive view of reading, Flavell (1976) and Brown (1978) identifies the type of reader to be shaped in schools today, in the domain of reading comprehension development. On one hand, the suggested meaning fixer is the one who is able to build knowledge of self as a reader and also of aspects of the reading task; and on the other, is proficient in the use of comprehension strategies and in the comprehension monitoring process of reading.

In order for the schools to shape this type of reader, primary and compulsory secondary school teachers have to equip students with a "toolbox" of strategies to help them monitor the meaning and repair any comprehension failure they came across, as LOE suggests. Those tools are but metacognitive strategies, playing an important role in making sense

of printing words, like authentic mental processes for the development of children's reading comprehension monitoring, as held by the OECD Programme for International Student Reading Competence Assessment PISA (2009).

Considering this, the purpose of this article is to provide a practical example of strategy instruction and classroom activities, using the strategy "We clarify the meaning", to teach readers how to shed light on words and portions of text they are unaware of its meaning. We conclude that explicit direct strategy instruction builds knowledge and metacognitive awareness in the process of comprehension monitoring (Calero, 2011).

The strategy has been segmented in five components which represent portions of the metacognitive knowledge to be monitored gradually by the students. Also, the components instruction includes modelling, working in groups, guided and independent practice in three phases: a) Teacher thinks aloud introducing the strategy and the meaning of each component; b) Students refine the use of the strategy components during selected reading group activities; c) Students self-assessment and goal-setting, noticing what component of this strategy they do well, and what they need to improve upon, in order to restore the meaning.
\end{abstract}

Key words: metacognition, reader as a meaning fixer, metacognitive strategies, strategy components, clarifying unknown words and portions of text, morphological awareness, rereading, comprehension monitoring.

\section{Le lecteur comme réparateur de la signification. Un exemple pratique}

\section{RÉSUMÉ}

$$
\text { d'enseignement direct des stratégies métacognitives }
$$

La métaphore du lecteur comme "réparateur» de signification - créée sous l'optique métacognitive fondée sur les études de Flavell (1976) et Brown (1978) - identifie, dans le cadre du développement de la compréhension en lecture, le type de lecteur que l'on souhaite créer de nos jours dans les établissements scolaires. Le type de lecteur proposé est, d'une part, capable de créer des connaissances sur la base de variables personnelles et de l'activité de 
lecture; et d'autre part, il est compétent dans l'utilisation de stratégies de lecture et du contrôle et régulation du processus de compréhension dans lequel il se trouve lorsqu'il lit.

Pour que cet archétype de lecteur soit possible, il est nécessaire que les enseignants de primaire et secondaire équipent leurs élèves des outils nécessaires, c'est-à-dire des stratégies ou ressources métacognitives leur permettant de superviser et contrôler la signification qu'ils construisent, ou réparer le cas échéant cette signification, lorsqu'il existe des problèmes de compréhension. Ces outils, ce sont les stratégies métacognitives, dont le rôle est essentiel en tant que processus de pensée associé au développement et contrôle de la compréhension en lecture, tel que précisé sur le Programme pour l'Évaluation Internationale d'Élèves PISA 2009.

C'est sur la base de ces prémisses que le présent article développe pas à pas un exemple pratique d'enseignement direct de la stratégie métacognitive : "clarifions la signification ", avec des activités permettant aux lecteurs de découvrir et d'apprendre à 《réparer » la signification de mots et de parties de texte où la compréhension de la lecture n'a pas été atteinte. La conclusion est que l'enseignement direct et explicite de stratégies métacognitives permet à l'élève de construire des connaissances et une conscience métacognitive, dans le processus de contrôle de la compréhension en lecture (Calero, 2011).

Cette stratégie s'articule sur cinq composantes, qui représentent des «portions de connaissances métacognitives» que les étudiants doivent utiliser et améliorer progressivement. L'enseignement de ces composantes exige des activités telles que le modelage par l'enseignant, le travail par groupes et les travaux pratiques individuels en trois étapes: a) l'enseignant présente le sens de la stratégie et l'utilisation de chacune de ses composantes, par une activité de réflexion orale; b) application et utilisation des différentes composantes par des activités en groupes réduits, avec des exercices de lectures préalablement choisies; et c), autoévaluation et établissement d'objectifs d'amélioration par l'élève, pour déterminer les composantes de cette stratégie qui sont appliquées avec succès, et celles qui doivent être améliorées pour rétablir la signification perdue.

Mots-clé: métacognition, le lecteur comme réparateur de la signification, les stratégies métacognitives, apprendre à apprendre, clarification de la signification, conscience morphologique, relecture, contrôle de la compréhension.

SUMARIO: 1. Introducción. 2. Dos metáforas complementarias del lector competente. 3. Justificación de la enseñanza directa y explícita de estrategias metacognitivas. 4. Desarrollo de la estrategia Clarificamos el significado. 4.1. Sentido de la estrategia y aspectos básicos. 4.2. Segmentación de palabras para descubrir su significado. 4.3. Releer el texto o continuar leyendo para recuperar la comprensión. 4.4. Criterios pedagógicos de desarrollo de esta estrategia. 4.5. Fase de clarificación. 4.6. Fase de aplicación y perfeccionamiento. 4.7. Fase de autoevaluación. 5. Conclusiones. Bibliografía.

\section{INTRODUCCION}

De acuerdo con el marco teórico de lectura del Programa para la Evaluación Internacional de Alumnos 2009 -PISA en sus siglas en inglés-, la metacognición es un componente esencial en el proceso de comprensión, y su contribución al desarrollo de la competencia lectora debe ser considerada de una forma decisiva en los centros escolares. El lector de este artículo encontrará la justificación teórica y un 
ejemplo de enseñanza directa de una estrategia concreta desde la perspectiva metacognitiva, basada en la reflexión y la propia experiencia docente. Este trabajo supone una aportación práctica a la idea de crear lectores competentes, y a la enseñanza de estrategias cognitivas y metacognitivas de comprensión lectora con el alumnado de educación primaria y secundaria obligatoria. Pretendemos, por tanto, llevar a la práctica reflexiones sobre cómo mejorar la comprensión lectora, con un ejemplo de enseñanza directa y explícita de la estrategia metacognitiva "clarificamos el significado" de palabras y segmentos del texto no comprendidos, con una propuesta de desarrollo de la misma.

Partimos de la idea de que la instrucción directa y explícita en estrategias metacognitivas de comprensión lectora incrementa y refuerza aquellos procesos de pensamiento que, sobre los propios recursos cognitivos, utilizan los estudiantes para apropiarse del significado del texto, de un modo reflexivo. Dichos procesos incluyen la supervisión y el control de la comprensión, junto con la autoevaluación de las propias destrezas que los lectores ponen al servicio de la comprensión del texto. En ese sentido nos planteamos que, en el manejo de la estrategia clarificación del significado, los lectores aprendan por un lado a reconocer e identificar el problema de comprensión que se les ha presentado durante la lectura del texto; y por otro, admitan que están atascados con una palabra o una idea, para lo cual necesitan echar mano de sus recursos cognitivos, o estrategias, en orden a remediar tal situación y recuperar así el significado perdido, como una conducta ordinaria de cualquier lector competente.

En consecuencia, defendemos que la escuela ofrezca a los estudiantes la oportunidad de reflexionar sobre cómo aprender a comprender, a través de la utilización de estos instrumentos o estrategias de desarrollo metacognitivo, en orden a despertar y estimular en ellos la consciencia de los procesos de conocimiento que están implicados en una tarea de naturaleza cognitiva y metacognitiva, como es la lectura.

\section{DOS METÁFORAS COMPLEMENTARIAS DEL LECTOR COMPE- TENTE}

La perspectiva cognitiva del aprendizaje, que se despliega hacia el último cuarto del siglo XX, adoptó como motivo de investigación fenómenos psicológicos tales como la motivación, la intencionalidad, el interés, la memoria, la atención, la comprensión y el control ejecutivo o "metacognición" de aquellos procesos cognitivos en los que se ve envuelto el estudiante. Con base en el enfoque constructivista del desarrollo de la comprensión lectora, que señaló el hecho de que el lector construye comprensión en interacción con el texto y el contexto, se crea la metáfora del lector como constructor de significado. Otros psicólogos cognitivistas ponen en marcha una nueva corriente de investigación sobre los procesos metacognitivos que pone en juego el lector estratégico -más comúnmente denominado competente- que le capacitan en el control y regulación del proceso de 
comprensión (Flavell, 1976) y Brown,1978). De su trabajo surge una nueva metáfora: la del lector como reparador de significado, para describir a un aprendiz competente que es capaz de controlar y regular el proceso cognitivo que sigue para comprender textos.

Más concretamente, una destreza metacognitiva como es la regulación de los procesos de comprensión lectora, o en otros términos, la supervisión y el control del lector sobre cómo está comprendiendo, ha sido motivo de una cierta preocupación en los ámbitos de la investigación pedagógica de las últimas décadas, al otorgar al pensamiento reflexivo de los estudiantes el valor suplementario de una innegable capacidad de acción consciente, que es necesario estimular en el medio escolar. De los trabajos llevados a cabo en este ámbito del aprendizaje, se concluye que la toma de conciencia de la sensación de saber (qué es lo que sé, cómo lo he aprendido, y qué es lo que no sé) representa para los estudiantes una experiencia metacognitiva importante, que mejora su desarrollo como aprendices competentes.

Sin duda, estas aportaciones han tenido consecuencias pedagógicas sobre cómo abordar en el aula la enseñanza de la comprensión lectora. De hecho, la teoría cognitiva ha interesado a los legisladores, y ha provocado la revisión de las normas educativas vigentes en determinados momentos, en la mayoría de los países europeos y latinoamericanos.

En España, las dos principales leyes educativas que desde el año 1990 se han implantado (LOGSE, 1990 y LOE, 2006, actualmente vigente), establecen un nexo de unión con el carácter epistemológico del aprendizaje, potenciando el hecho de que el alumno, además de construir significado, debe ser consciente de sus propias realidades y capacidades como aprendiz. En consecuencia, la LOE recoge en su literatura la esencia de la metáfora del lector como reparador del significado -, cuyas consecuencias suponen un avance en el ámbito de los procedimientos de enseñanza de esta competencia. Por un lado, la promulgación de la LOGSE en el año 1990 supuso un revulsivo a la concepción tradicional del aprendizaje de la lectura. Comprender textos, se decía en ese momento, supone modificar los esquemas de conocimiento que el alumno posee, en concurrencia con otros nuevos que la lectura le ofrece, dado que el significado está sólo parcialmente determinado por el texto en sí. Leer, por tanto, debía ser un proceso cognitivo de índole constructivo, caracterizado por la formación y comprobación de hipótesis elaboradas por el propio estudiante, junto con la asimilación del nuevo conocimiento al esquema correspondiente.

La mayoría de los enfoques interactivos de desarrollo de la comprensión lectora que se invocaban, y que defendían un procesamiento de la lectura dirigido simultáneamente por los datos explícitos del texto y por los conocimientos previos del lector, adoptaron la metáfora del lector como constructor de comprensión que se apoya en sus esquemas de conocimiento. Los esquemas no son sino estructuras conceptuales que se activan en función del nuevo conocimiento al que se accede (Alonso, 1985,7): 
Con esta perspectiva, se abogaba por la idea de que el significado no reside en las palabras, ni en los párrafos, ni siquiera en el texto considerado globalmente, sino que reside en el lector, que activamente construye o representa la información del texto, acomodándola a su conocimiento del mundo y a sus propósitos de comprensión en un momento dado. De ese modo, la construcción del significado es el resultado de la interacción entre el texto, los esquemas de conocimiento y el contexto de varios tipos: lingüistico, situacional, actitudinal, requerimiento de la tarea, etc.

En consecuencia, se promovía la utilización de diseños de trabajo en el aula en los que el docente debía adoptar el papel de facilitador o modelador de estrategias cognitivas de aprendizaje, para que el alumno elaborara significado a partir de sus esquemas previos, en un contexto en donde se llevasen a cabo tareas de construcción compartida de significado. De hecho, en los propios criterios de evaluación de esa ley educativa se abogaba por la utilización de estrategias tales como: ser conscientes del propósito de la lectura, utilizar indicadores textuales y no textuales para formular hipótesis previas a la lectura, y avanzar o retroceder en el texto para reforzar la comprensión. Mucha fue la inversión en recursos económicos y de personal que distintas instituciones públicas y privadas destinaron a la realización de cursos de formación del profesorado, durante los años 80-90 en España, en orden a adaptar las metodologías y los recursos pedagógicos disponibles a la nueva concepción de aprendizaje que la LOGSE planteaba.

Por otra parte, la Ley Orgánica de Educación LOE (2006) recogió la perspectiva constructivista del aprendizaje de la LOGSE, prestó una mayor atención a los procesos de adquisición de la lectura, y dio ese salto cualitativo al otorgar ahora a este aprendizaje una dimensión metacognitiva, proponiendo la necesidad de desarrollar en los alumnos la capacidad de conocimiento, control y regulación de su propio proceso de comprensión lectora, tanto en la etapa de primaria como la de secundaria obligatoria, con la inclusión en su articulado de la competencia básica de aprender a aprender.

Por supuesto, desarrollar esta competencia supone dotar al alumno de habilidades metacognitivas (Flavell, 1976, 1979, 1993; Brown, 1980, 1987; Jacobs y Paris, 1987; Baker \& Brown, 1984a, 1984b; Pressley et al. 1998; Israel, 2007; Jaramillo et al.,2006; Vidal et al.,2010).

En este contexto de aprendizaje, el lector aprende a reflexionar sobre la tarea, sobre él mismo como aprendiz, y sobre las estrategias de aprendizaje a utilizar, con la intención de regular dichos conocimientos y saber cómo generalizarlos a otras nuevas tareas escolares, de un modo cada vez más efectivo y autónomo. En este sentido, cuando en el ámbito del desarrollo de la comprensión lectora la ley establece el currículo del área de Lengua Castellana y Literatura (Orden Ministerial de 2007,3153), al referirse a la competencia básica de aprender a aprender, el lenguaje escrito es concebido como la base del pensamiento y del conocimiento, para resaltar 
posteriormente la importancia de la regulación metacognitiva en el aprendizaje; es decir, la comunicación con uno mismo, el análisis de problemas, la elaboración de planes y la toma de decisiones:

El acceso al saber y a la construcción de conocimientos mediante el lenguaje se relaciona directamente con las competencias básicas de aprender a aprender. El lenguaje escrito está en la base del pensamiento y del conocimiento, y permite comunicarse con uno mismo, analizar problemas, elaborar planes y emprender procesos de decisión. En suma, regular y orientar nuestra propia actividad con progresiva autonomía.

Pero el debate actual en las aulas sigue estando en cómo desarrollar tal competencia, en cómo llevar a la práctica del aula lo que la Orden por la que se establece el currículo de educación Primaria MEC (2007, 31497) entiende por aprender a aprender:

La toma de conciencia, gestión y control de las propias capacidades y conocimientos, desde un sentimiento de competencia o eficacia personal, incluye tanto el pensamiento estratégico, como la capacidad de autoevaluarse y el manejo de un conjunto de recursos y técnicas de trabajo intelectual, todo lo cual se desarrolla a través de experiencias de aprendizaje conscientes y gratificantes, tanto individuales como colectivas.

O también en la Orden del currículo en la educación Secundaria Obligatoria (2007,31692): "Ser consciente de lo que se sabe, y de lo que es necesario aprender, de cómo se aprende, y de cómo se gestionan y controlan de forma eficaz los procesos de aprendizaje, optimizándolos y orientándolos a satisfacer objetivos personales.

Veamos de un modo esquematizado en la figura 1 cuáles son los aspectos que definen al lector competente en la literatura de la orden ministerial de Primaria. Un somero análisis nos lleva a concluir que, en mucho, esos aspectos recogen las aportaciones del enfoque metacognitivo, acerca de los procesos generales implicados en el aprendizaje. Las definiciones que en esta norma pedagógica se dan de significado, implicaciones y los requerimientos para aprender a aprender, explican suficientemente las dimensiones del conocimiento metacognitivo (declarativo, procedimental y condicional), y su autorregulación, como procesos de aprendizaje básicos que se sostienen en dicho enfoque: Flavell,1976, 1979, 1993; Brown, 1980, 1987; Jacobs y Paris, 1987; Baker \& Brown, 1984a, 1984b; Pressley et al. 1998; Israel, 2007; Jaramillo et al 2006; Vidal et al., 2010. 
Competencia aprender a aprender

\begin{tabular}{|l|l||}
\hline \hline \multirow{5}{*}{ Significado } & $\begin{array}{c}\text { Significa ser consciente de: } \\
\text { - Lo que se sabe. }\end{array}$ \\
- Lo que es necesario aprender. \\
• Cómo se aprende. \\
• Cómo se gestionan y controlan de forma eficaz los \\
procesos de aprendizaje concreto.
\end{tabular}

Fig. 1: Dimensiones de la competencia aprender a aprender.

En otras palabras, lo que los legisladores educativos plantean es que hay una competencia en el aprendizaje de la lectura, que es básica para el desarrollo intelectual y académico de los estudiantes, que va a fortalecer y expandir su capacidad de comprensión lectora, y que debe ser entrenada en las aulas. Se trata de la competencia metacognitiva, que da sentido al concepto de aprender a comprender.

Complementaria a esta idea del lector reflejada en la LOE, recientemente el Programa para la Evaluación Internacional de Alumnos (PISA, 2009) aboga por la enseñanza directa y explícita de las estrategias metacognitivas, para mejorar la comprensión lectora e independizar al lector en el procesamiento de los textos que lee. De acuerdo con el Instituto de Evaluación $(2010,96)$ : 
El constructo metacognición y las preguntas propuestas para su inclusión en PISA 2009 se centran especificamente en leer para aprender. El conocimiento metacognitivo es una condición "sine qua non" para un aprendizaje reflexivo y estratégico. Por tanto, no resulta sorprendente que se hayan descubierto relaciones sólidas y significativas entre el conocimiento metacognitivo, la conducta estratégica en un ejercicio de procesamiento de textos y el recuerdo del texto.

De ese modo, en el año 2009 la evaluación PISA, llevada a cabo en 65 países, incluyó por primera vez la competencia metacognitiva en las tareas de comprensión lectora, justificando esta inclusión por las propias investigaciones previas que realizó en los años 2000 y 2003. Así, en el año 2000, a los estudiantes alemanes que participaron en la evaluación se les aplicó un instrumento de medida del conocimiento metacognitivo que habían elaborado sobre la comprensión del texto, obteniéndose una correlación $\mathrm{r}=0,51$ entre el rendimiento en comprensión y el conocimiento metacognitivo expresado por el alumnado sobre la tarea. Del mismo modo, otros resultados en 2003 confirmaron una correlación muy similar.

El Instituto de Evaluación $(2010,96)$ respalda y defiende estas conclusiones cuando concluye: "En PISA 2009, la recopilación de datos sobre aquellos aspectos de la metacognición, cuya relación con la comprensión lectora está demostrada, puede proporcionar la clase de información utilizada para mejorar la competencia lectora y cumplir, así, uno de los objetivos de PISA: facilitar a los responsables políticos las estrategias que sirven para mejorar los resultados educativos de los alumnos". Como consecuencia, se establece un perfil de lector competente, implícitamente recogido en dicho informe internacional. Así, en el citado documento del Instituto de Evaluación (2010,20), se define la competencia lectora en PISA como: "la capacidad de un individuo para comprender, utilizar, reflexionar y comprometerse con textos escritos para alcanzar sus objetivos, desarrollar sus conocimientos y potencial, y participar en la sociedad".

Esta competencia estratégica y reflexiva no se desarrolla espontáneamente en el lector, es necesario enseñarla. Para ello, hay que poner en valor todas aquellas prácticas escolares que preparen al alumno, desde el comienzo de la enseñanza de la lectura, para dar respuestas a situaciones y problemas cercanos a la vida real, como un proceso de control y seguimiento de la comprensión lectora que construye. Más concretamente, cuando determinamos que un estudiante posee competencia lectora, estamos describiéndolo con la habilidad para reflexionar críticamente sobre lo que lee, para supervisar y controlar sus posibles fallos de comprensión lectora, y para usar el conocimiento adquirido como un instrumento que le posibilite para alcanzar metas individuales. Es decir, un lector que es consciente de que está aprendiendo a comprender, y que además tiene una cierta habilidad para controlar y autorregular su capacidad lectora.

Sin embargo, es constatable que muchos alumnos no desarrollan esta capacidad. Por tanto, es necesario enseñarles en la práctica diaria del aula a aprender a 
comprender, o a saber comprender, como una competencia básica que hay que entrenar mediante el diseño de programas de desarrollo de habilidades metacognitivas. Básicamente, porque aquellos que no poseen estas destrezas no son conscientes de que deben hacer conexiones entre lo que leen y lo que conocen. A la vez, tampoco descubren la necesidad de contrastar lo que leen con lo que piensan o sienten. Asimismo, raras veces se detienen a buscar en el texto las pistas que les lleven a recuperar la comprensión perdida, ni a evaluar la comprensión de los materiales de lectura a los que se enfrentan, o a reflexionar sobre el uso que han hecho de las estrategias que utilizaron para comprender. Del mismo modo, cuando leen, y se encuentran con alguna parte del texto de difícil comprensión, siguen adelante pensando que una única lectura es más que suficiente para entender lo que han leído.

Por el contrario, los lectores competentes o metacognitivos establecen un objetivo para su lectura y saben cómo utilizar estrategias para comprender. Así por ejemplo, saben que la activación de sus ideas previas y el contraste posterior con lo leído mejorará su comprensión; siendo además capaces de plantearse a sí mismo preguntas sobre la lectura, para darle sentido. Igualmente, valoran la importancia de establecer conexiones entre lo que leen y lo que saben; a la vez que se detienen a reparar la comprensión perdida, y muestran un cierto nivel de reflexión sobre su propia competencia en el manejo de aquellas estrategias más útiles para comprender (Calero, 2011). Un lector que es hábil para aprender a comprender gana confianza, está más motivado y se hace cada vez más independiente en el desarrollo de la tarea. Esa independencia le va a permitir en el futuro perseguir y alcanzar aquellas metas de conocimiento y regulación de comprensión que se plantee.

\section{JUSTIFICACIÓN DE LA ENSEÑANZA DIRECTA Y EXPLÍCITA DE ESTRATEGIAS METACOGNITIVAS}

Son varios los estudios que han establecido una relación estrecha entre desarrollo metacognitivo y mejora de la competencia lectora, que abogan por un procedimiento de instrucción directa y explícita en el manejo de estrategias metacognitivas.

Brown, Palinscar \& Ambruster (2006) llevaron a cabo tres estudios de enseñanza directa y explícita de estrategias metacognitivas, en los que los alumnos del grupo experimental fueron entrenados, a través del procedimiento de enseñanza recíproca, en el uso de cuatro estrategias metacognitivas: predecir, cuestionar, clarificar y resumir. El entrenamiento que llevaron a cabo fue intensivo y extensivo. Las actividades fueron diseñadas particularmente para los alumnos, procurando una especial atención en el desarrollo de destrezas metacognitivas. De ese modo, se informó expresamente a los lectores por qué las actividades que llevaban a cabo eran útiles, y se cuidó expresamente el entrenamiento en actividades de autorregulación, para que aprendieran a controlar su propia comprensión. Los alumnos de los grupos 
experimentales de estos tres estudios mejoraron significativamente sus niveles de conocimiento y regulación, en las tareas de comprensión lectora.

Por otra parte, el Informe de la Comisión Nacional de Lectura de EE.UU. (2000), citado por el Instituto de Evaluación $(2010,96)$, llega a la conclusión de que es necesaria la enseñanza directa de estrategias metacognitivas, tras haber analizado un conjunto de investigaciones que habían estudiado la mejora de la instrucción en comprensión lectora: "La escasa competencia lectora se puede mejorar mediante la enseñanza explícita de destrezas metacognitivas. Es decir, cuando a los lectores se les enseñan estrategias cognitivas y metacognitivas, el aumento de su nivel de comprensión es mucho mayor que el de aquellos alumnos con los que se han seguido procedimientos de instrucción convencionales".

En consecuencia, los lectores de educación primaria y secundaria obligatoria deben ser enseñados, paso a paso, de un modo directo, a tomar conciencia de que, por ejemplo, prever el contenido de un texto supone saber que la portada, el título, la lectura de la contraportada, les proporcionan pistas que les llevan a establecer una hipótesis previa de su contenido. También, que estableciendo conexiones entre lo que dice el texto y lo que ellos piensan, sienten o creen, incrementa su comprensión. O que hacerse a sí mismo preguntas y buscar pistas textuales, que aclaran el significado de palabras desconocidas y partes de un texto -como planteamos en la siguiente sección- es una estrategia importante para controlar el proceso de comprensión que puede llevar a cabo (Calero, op.cit.)

Duffy (2002) identifica cuatro conocimientos esenciales que debe construir el lector, en todo procedimiento efectivo de enseñanza directa y explícita de estas estrategias:

- Comprender el sentido de la estrategia de un modo significativo.

- Que adviertan por qué están aprendiendo las estrategias y cómo les ayudan al leer

- Que aprendan a usar las estrategias paso a paso

- Que sepan cuándo y dónde pueden ser utilizadas las estrategias

- Que autoevalúen el uso que hacen de las estrategias, de tal modo que puedan controlar y mejorar su comprensión.

Estas destrezas se logran a través de un proceso de transferencia gradual de la responsabilidad en el manejo de estrategias, desde el profesor hacia el estudiante (Duke et al., 2011). Decimos que esa transferencia es gradual porque, en un primer momento es el docente quien, durante el tiempo necesario, asume tareas de modelado en la aplicación de cualquier estrategia, además de la supervisión y guía posterior en el cómo los estudiantes las utilizan; para, finalmente, ir transfiriéndoles de un modo paulatino la responsabilidad de su uso a cada uno de ellos. Esa transferencia progresiva y gradual la concretamos en cinco fases: 
- Descripción explícita por parte del profesor del qué de la estrategia (su sentido), cuándo y cómo utilizarla: "Antes de empezar a leer, yo soy capaz de predecir el contenido de esta narración porque observo sus dibujos, leo la contraportada, y me están dando ideas. Los dibujos y lo que dice aquí en la contraportada son pistas muy importantes que me ayudan a predecir y a comprender mejor lo que voy a leer después..."

- Modelado de la conducta de utilización de los distintos componentes de la estrategia por parte del profesor, u otro alumno: "De este libro que vamos a leer yo utilizo el componente 'lo que sé del tema'. Hace una semana leí otro libro con títulos de capítulos parecidos, y yo predigo que este nuevo libro que ahora estoy leyendo tratará sobre lo mismo: el por qué las aves emigran"

- Práctica guiada y supervisada en el uso de los componentes de la estrategia, transfiriendo gradualmente el cómo hacer al lector: "Bien, yo he usado para hacer predicciones el componente 'las ilustraciones y lo que dice la contraportada'. Ahora voy a ayudaros a que vosotros tres hagáis también predicciones sobre esta lectura, y cuando acabéis dialogamos y contrastamos las que yo hice con las que vosotros proponéis".

- Trabajo cooperativo en pequeños grupos usando los componentes de la estrategia, y reflexión conjunta posterior del grupo-clase sobre el trabajo de cada grupo: "Cada grupo habéis elegido un libro de la biblioteca del aula. Vuestro trabajo consiste en hacer predicciones utilizando éste componente. Una vez que hayáis acordado cuáles son las mejores predicciones, el responsable del grupo las expondrá, y justificará al resto de la clase por qué las habéis elegido"

- Práctica independiente del alumnado en el uso de la estrategia y autoevaluación de su propia competencia: "Me gustaría que me dijeras cuáles fueron las predicciones que tú has hecho mientras leías este primer capítulo del libro, y qué componentes de esta estrategia son los que mejor sabes utilizar, y en cuáles crees tú que deberías mejorar su uso".

De un modo más gráfico, en la figura 2 representamos estas fases de transferencia gradual en la responsabilidad del manejo de dichas estrategias 


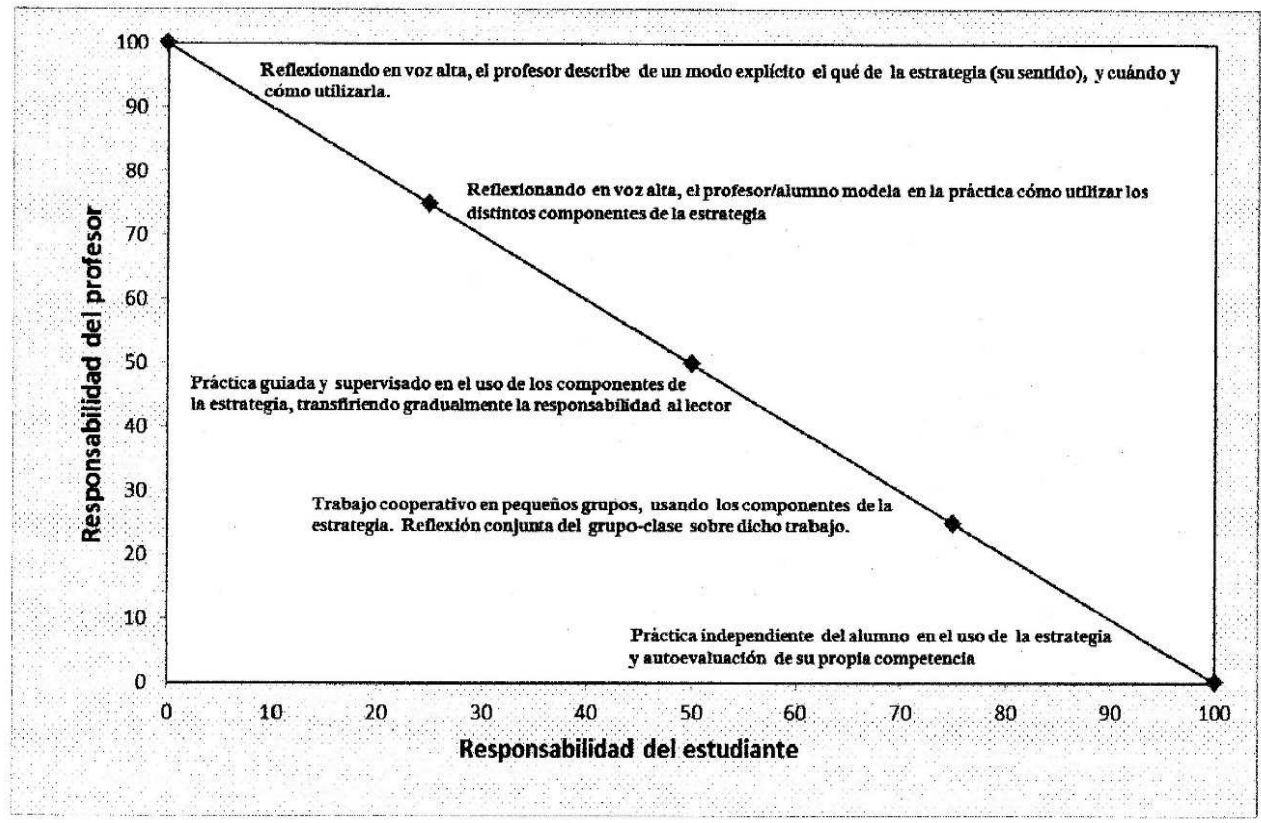

Figura 2. Adaptada de "Essential elements of fostering and teaching reading comprehension" N.K. Duke, P.D. Pearson, S.L. Strachan y A.K. Bilman (2011). En What Research Has to Say about Reading Instruction (4 ${ }^{\text {th }}$ edition), 51-93. IRA.

\section{DESARROLLO DE LA ESTRATEGIA CLARIFICAMOS EL SIGNIFICADO}

\subsection{Sentido de la estrategia y aspectos básicos}

En el desarrollo de la estrategia "clarificamos el significado" proyectamos una secuencia práctica de trabajo, y algunos materiales que promueven en el lector la capacidad de conocer, aplicar y autoevaluar aquellos procesos de conocimiento implicados en una tarea cognitiva, como es la de controlar y/o recuperar la comprensión de un texto que se está leyendo.

Comencemos precisando el significado de esta estrategia y su contribución a la mejora de la comprensión lectora. En primer lugar, una de las características de los lectores que son hábiles en el proceso de clarificación de la comprensión es que han adquirido una destreza que viene en llamarse conciencia morfológica de las palabras. Así, son capaces de manipular su estructura, y desarrollan habilidades que implican un uso estratégico de sus constituyentes morfológicos y semánticos. Por ejemplo, se muestran diestros para analizar los componentes morfológicos de una palabra desconocida tal como hidrocefalia, para poder encontrar las pistas semánticas de "hidro", que alude a agua, y "cefalia", que se refiere a "cabeza".

Con esas pistas semánticas parciales reconstruyen estratégicamente el significado de dicha palabra, para poder elaborar una hipótesis aproximada de su 
significado. Además han aprendido que releer, o seguir leyendo para descubrir otras pistas o indicios dentro del texto que clarifiquen el significado, es una estrategia muy útil para recomponer la comprensión perdida de una parte del mismo. De acuerdo con Kelley \& Clausen-Grace (2007), cuatro son los aspectos básicos de orden metodológico que hemos contemplado para diseñar el trabajo con esta, u otra estrategia:

a. La segmentación de la estrategia en componentes, para facilitar el sentido que tiene, y poder así secuenciar y facilitar su aprendizaje.

b. La actividad de modelaje del profesor, mediante la estrategia de pensar en voz alta.

c. Los materiales de apoyo, para posibilitar la comprensión y el manejo de cada componente: el mural y la plantilla individual de la estrategia.

d. La enseñanza de la estrategia en tres fases: la primera, para descubrir a los lectores el sentido y la aplicación de los componentes de la estrategia; la segunda, para que los alumnos, en trabajo cooperativo, adquieran una experiencia práctica en el uso de dichos componentes; y la tercera, para que aprendan a autoevaluar su competencia en el manejo de dichos componentes y la estrategia globalmente.

Es necesario señalar que son muchos los alumnos que, cuando fallan en la comprensión de lo que están leyendo, no están acostumbrados, o no se les ha enseñado expresamente a detenerse para reflexionar acerca de dónde pueden estar las pistas que el propio texto les puede ofrecer para restablecer la comprensión perdida. En muchos, esta conducta viene motivada por la falta de experiencias de aprendizaje en el uso de las estrategias adecuadas para tal fin en el aula. En consecuencia, es indispensable enseñarles a utilizar aquellas que sean más convenientes para reparar el significado perdido, tanto en el ámbito del trabajo con las palabras desconocidas del texto, como en el del contexto de las frases en el que dichas palabras están incluidas.

Desde un punto de vista práctico, la enseñanza de dichas estrategias conlleva el objetivo de que, mientras lee, el alumno se ejercite en:

- Saber identificar el problema de comprensión, y admitir que está atascado con alguna palabra, o una idea del texto.

- La conciencia de que debe recurrir al uso de una estrategia que ya ha aprendido, para remediar tal situación.

De ese modo, los docentes debemos diseñar experiencias de aprendizaje que ayuden a los alumnos a controlar la comprensión que van generando, y a enseñarles cómo identificar aquellos problemas que se les van presentando en relación con a) determinadas palabras del texto que les resultan desconocidas, y b) algunas partes del texto en donde dichas palabras se encuentran -frases, parágrafos- de difícil comprensión. Es decir, dado que una de las principales variables que explican las carencias en comprensión lectora del alumnado es el bajo nivel de vocabulario que 
presentan, debemos motivarles a ser investigadores que buscan el significado de palabras desconocidas, proporcionándoles instrumentos de pensamiento -estrategiasque les clarifiquen las pistas de significado internas de las mismas -o externas a ellas- que en muchos casos se ocultan dentro, o en el resto de palabras del texto. O dicho de otro modo, el uso de destrezas variadas de análisis del contexto en el que las palabras se encuentran permite a los estudiantes abandonar actitudes pasivas frente al mismo, y adoptar una actitud activa y dinámica en el esclarecimiento de la comprensión perdida. No se nos debe escapar el hecho de que la media de palabras que aproximadamente adquieren los estudiantes de estas etapas es de unas 3.000 al año -unas 100 por semana-. Y muchas de ellas provienen de la experiencia lectora escolar y personal.

Sin embargo, lamentablemente los procedimientos clásicos de enseñanza del vocabulario, basados por una parte en la búsqueda del significado de palabras en el diccionario; o en el aprendizaje de dicho significado en tareas de rellenado de fichas con frases que incluyan esas palabras desconocidas, no han dado los resultados más idóneos para la mejora de la comprensión lectora. Por ello son muchos los lectores a los que nunca se les ha dado la posibilidad de adquirir destrezas tales como:

1. Segmentar y analizar los componentes de una palabra (prefijos, sufijos o raíz) para buscar en ellos porciones del significado de las palabras desconocidas.

2. Releer el texto o continuar leyendo, para localizar aquellas pistas textuales y no textuales que nos hacen generar hipótesis del significado de palabras o frases, a partir del contexto literal de porciones del texto, en donde algunos sintagmas -nominales, verbales, adverbiales, etc.pueden proporcionar al lector indicios suficientes para construir la comprensión perdida.

En consecuencia, se requiere una enseñanza intencional directa y explícita del vocabulario desconocido, a través del uso de estrategias que den al lector autonomía en el establecimiento de conexiones semánticas en el interior de la palabra y entre las que el texto incluye. Los cinco componentes a trabajar, en los que hemos segmentado esta estrategia (ver figura 3) recogen el objetivo básico de desarrollar en los estudiantes la toma de conciencia del valor de esas dos destrezas metacognitivas básicas anteriormente indicadas, para clarificar el significado perdido.

\subsection{Segmentación de palabras para descubrir su significado}

Segmentar una palabra para analizar sus distintos componentes de carácter morfológico y semántico es una de las destrezas de los buenos lectores. La habilidad que esta estrategia genera se la conoce como conciencia morfológica, y representa un buen predictor del rendimiento ulterior en comprensión lectora del alumnado de cursos superiores de educación primaria y secundaria obligatoria (McCutchen \& Logan (2011). 
MURAL / PLANTILLA INDIVIDUAL: CLARIFICAMOS EL SIGNIFICADO Alumnola:

\begin{tabular}{|l|l|}
\hline $\begin{array}{l}\text { PENSAMOS EN VOZ ALTA } \\
\text { Yo clarifico el significado... }\end{array}$ & TOTAL \\
\hline $\begin{array}{l}\text { Descomponiendo las palabras en } \\
\text { partes para aclarar su significado }\end{array}$ & \\
\hline Volviendo a leer para comprender & \\
\hline $\begin{array}{l}\text { Continuando la lectura para } \\
\text { descubrir otras pistas y comprender } \\
\text { mejor }\end{array}$ & \\
\hline $\begin{array}{l}\text { Compartiendo con mis compañeros } \\
\text { el significado }\end{array}$ & \\
\hline $\begin{array}{l}\text { Buscando el significado de palabras } \\
\text { en el diccionario o en internet }\end{array}$ & \\
\hline
\end{tabular}

Figura 3: Mural y Plantilla individual de la estrategia.

Ya en el año 1987 los trabajos de Wysocki y Jenkins demostraron que la habilidad de los alumnos de educación primaria para aprender el significado de las palabras en tareas de comprensión lectora se incrementaba con un entrenamiento previo en análisis morfológico y reconocimiento de familias de palabras.

En términos generales, el análisis de segmentos morfológico/semánticos de las palabras representa una aportación cualitativa al proceso de desarrollo del vocabulario general del lector que, a la vez, le posibilita la construcción de hipótesis aproximadas de significado y, como consecuencia, la mejora de su comprensión del texto. El lector que posee conciencia morfológica es diestro para reflexionar sobre aquellos segmentos significativos de una palabra desconocida, tales como su prefijo, sufijo o su raíz. En este sentido, esa reflexión conlleva dos operaciones estratégicas: la segmentación y el ensamblaje posterior de la palabra, como destrezas importantes que le sirven para descubrir el significado perdido. Es decir, por un lado es capaz de manejar la estructura de las palabras; y por otro, es hábil para reflexionar sobre los componentes semánticos de dicha estructura, como factores de un uso estratégico de los constituyentes morfológicos y semánticos de las palabras. Así, ante una palabra desconocida como inmaterial, que consta de un prefijo -in- y de una raíz - material- 
el alumno es capaz de analizar y reflexionar sobre esos segmentos de la palabra, cargados de significado - "in", como partícula de negación, junto a la raíz de la palabra- para descubrir su significado.

Otra estrategia de análisis y reflexión es la que se aplica a palabras cognadas (palabras que en otros idiomas distintos al español tienen una ortografía parecida y un significado igual o muy parecido). En una escuela multicultural como la que actualmente tenemos, la existencia de alumnos con otras lenguas (latinoamericanos, europeos y de otros continentes), facilita el uso de esta estrategia, como un recurso para incrementar el vocabulario de los estudiantes y su comprensión lectora. Es una evidencia que existen muchas palabras desconocidas para los alumnos entre idiomas, como por ejemplo el español, el inglés, el francés o el portugués, que a veces utilizan raíces griegas y latinas comunes, y que comparten además prefijos y sufijos audiólogo, audiologist, audiologiste, audiolgista-. Por tanto, estas similitudes morfológicas y semánticas deben ser enseñadas a los lectores de estas etapas educativas. Para trabajar esta estrategia es muy útil interpelar a los estudiantes de esas otras lenguas cuando se encuentren un cognado en una tarea de lectura, para que aporten la palabra correspondiente en su lengua. La reflexión y el análisis en grupo de este tipo de palabras desconocidas, señalando las diferencias morfológicas sutiles que existen entre sus diferentes cognados, enriquece no sólo el vocabulario de los alumnos de habla española, sino también el del alumnado de otras lenguas.

\begin{tabular}{||l|l|l||}
\hline \hline Prefijo & Significado & Ejemplo \\
\hline ad- & proximidad, contiguo & ad-yacente \\
\hline ab-, abs & separar. Evitar & abs-temio \\
\hline ante- & Delante & ante-sala, ante-poner \\
\hline bi, bis- & dos o doble & bi-furcación, bilabial, bipolar \\
\hline cuadri- & cuatro & cuadri-látero \\
\hline des- & denota negación o significado contrario & des-acuerdo, des-contento \\
\hline endo- & internamente & endo-carpio \\
\hline ex- & afuera, que sobra & ex-tramuros, ex-cedente \\
\hline hemi- & mitad & hemi-stiquio \\
\hline in- & negación & in-frecuente, im-probable \\
\hline infra- & por debajo de & infra-rrojo, infra-humano \\
\hline intra- & dentro & intra-muros \\
\hline multi- & de muchos & multi-color \\
\hline pos-, post- & detrás o después de & pos-data, post-realismo \\
\hline pre- & que antecede & pre-juicio, pre-suponer \\
\hline re- & repetición & re-cargar, re-nombrar \\
\hline retro- & hacia atrás & retro-activo, retro-alimentar \\
\hline sub- & bajo & sub-marino, sub-terráneo \\
\hline super-, & que está por encima & super-dotado, supra-rrenales \\
\hline supra- & uno & uni-celular \\
\hline uni- & que rebasa & ultra-mundo \\
\hline ultra- & & \\
\hline & & \\
\hline
\end{tabular}




\begin{tabular}{|l|l|l||}
\hline viz-, vice- & en lugar de & vice-presidente, viz-conde \\
\hline yuxta- & junto a & yuxta-posición \\
\hline
\end{tabular}

Figura 4: prefijos más frecuentes en español

\begin{tabular}{|c|c|c|}
\hline Sufijo & Significado & Ejemplo \\
\hline -áceo & semejante, con apariencia & ros-áceo \\
\hline -aco & relativo a, perteneciente a & Policí-aco \\
\hline -aje & conjunto de, medida o proporción & rop-aje, kilometr-aje \\
\hline- al & lugar donde existe o abunda & patat-al, tropic-al \\
\hline -algia & dolor de & neur-algia \\
\hline -ario & relativo a, perteneciente & $\begin{array}{l}\text { legion-ario, arrendat- } \\
\text { ario }\end{array}$ \\
\hline -arquia & mando & $\begin{array}{l}\text { jer-arquia. } \\
\text { arquia }\end{array}$ \\
\hline -bilidad & cualidad de & $\begin{array}{l}\text { ama-bilidad afa- } \\
\text { bilidad }\end{array}$ \\
\hline -cardio & relativo al corazón & taqui-cardio \\
\hline -cola & habitante de, que cultiva o cría & arborí-cola, apí-cola \\
\hline -dero & lugar donde se.. & $\begin{array}{l}\text { verte-dero, inverna- } \\
\text { dero }\end{array}$ \\
\hline -eza & cualidad de & trist-eza, firm-eza \\
\hline -fobia & temor, huida & $\begin{array}{l}\text { clausto-fobia, xeno- } \\
\text { fobia }\end{array}$ \\
\hline -latra & que adora $\mathrm{a}$ & Idó-latra, egó-latra \\
\hline$-\log 0,-\operatorname{loga}$ & $\begin{array}{l}\text { forman nombres que designan a la persona que } \\
\text { cultiva una ciencia }\end{array}$ & antropó-logo \\
\hline -oma & asociado a palabras que implican un tumor & fibr-oma \\
\hline -pata & tipo de médico especialista & neuró-pata \\
\hline -pedia & $\begin{array}{l}\text { conjunto de conocimientos, técnica para corregir } \\
\text { defectos }\end{array}$ & $\begin{array}{l}\text { enciclo-pedia, orto- } \\
\text { pedia }\end{array}$ \\
\hline -teca & lugar donde se guarda algo & $\begin{array}{l}\text { pinaco-teca, filmo- } \\
\text { teca }\end{array}$ \\
\hline -udo, -uda & abundancia de algo & pel-udo, forz-udo \\
\hline -voro, vora & que se alimenta de & herbí-voro, carní-voro \\
\hline
\end{tabular}

Figura 5: sufijos más frecuentes en español

\subsection{Releer el texto o continuar leyendo para recuperar la comprensión}

La reflexión sobre componentes morfológicos de las palabras desconocidas no es la única estrategia que los alumnos pueden utilizar para averiguar el significado perdido. Es una evidencia científica que, para recuperar el significado de palabras o frases, los buenos lectores también hacen uso del contexto literal en el que la palabra está comprendida, para inferir y restaurar el significado (Zwiers (2010). La consecuencia es que los lectores estratégicos incrementan su comprensión, a partir de la detección y el conocimiento de determinadas marcas textuales en forma de palabras, expresiones, etc., que el propio texto les ofrece para poder utilizarlas como pistas que le ayudan a investigar el significado particular de la palabra o de la frase.

Algunas de esas pistas estratégicas a enseñar a los estudiantes, para despertarles esa conducta investigadora sobre el significado oculto son las siguientes: 
1. El autor del texto explica o define la palabra desconocida en la misma frase en la que se encuentra. Para ello, introduce algunas pistas textuales:

- Los verbos ser, estar o tener en sus formas: "es, son, representa, tiene, tienen", en ejemplos como:

- "Un metrónomo es un aparato utilizado para indicar tempo o compás de las composiciones musicales"

- "Una flor que tiene los pétalos soldados total o parcialmente es considerada como gamopétala".

- El verbo significar en sus formas: "significa, significan...", en ejemplos como:

- "el "pedigrí significa que el animal es de raza pura, no mezclado"

- El verbo definir en sus formas: "se define por/como, es definido por/como", en ejemplos como:

- "la artritis se define por los signos clínicos de rubor (enrojecimiento), calor, dolor y tumor (hinchazón) que afecta a una $\mathrm{o}$ varias articulaciones del organismo.

2. El autor recurre a sinónimos para explicar el significado de la palabra desconocida. Estas son las pistas textuales que suelen incluirse:

- Adverbios, nexos causales o expresiones como: "es decir, o, en el sentido de, en otras palabras, porque", en ejemplos como:

- "Su actitud beligerante, es decir, sus constantes ganas de crear conflictos, llamaron la atención de la gente"

- "La desventaja era franca, en el sentido de que era evidente"

- "Su megalomanía le atrajo enemistades. En otras palabras, su sensación de superioridad provocó rechazos entre sus amigos".

- "Su comportamiento llegó al paroxismo porque tras mostrarse inquieto se dejó arrebatar de una pasión perdida por arrojar los platos por la ventana"

- Una frase escrita entre comas, o entre paréntesis, como en este ejemplo:

- neumonía, una inflamación del pulmón, es una causa importante de mortalidad entre los ancianos".

3. El autor utiliza antónimos (el significado contrario de la palabra desconocida), para deducir el significado correcto, aportando las siguientes pistas textuales:

- Expresiones de significado contrario y negaciones como: "por una parte...por otra parte, y sin embargo, en ejemplos como:

- "Era una persona muy suspicaz, pero por otra parte muchas veces se mostraba confiado" 
- "Mi primo era altanero y $\sin$ embargo en casa era sencillo y humilde.

4. La palabra desconocida se halla dentro de una frase o parágrafo, en los que se ha establecido una relación causa-efecto. El significado de dicha palabra se puede deducir si motivamos a los lectores a pensar en las causas que generan determinados efectos. Algunas de las pistas textuales que se suelen incluir en las frases son: "por eso, por consiguiente, por esta razón, de tal modo que”, en ejemplos como:

- "Constantemente su conducta era la de zaherir a sus compañeros, y por eso los humillaba, despreciaba y ofendía cuando se los encontraba en la calle"

- "Jerónimo se caracterizaba por su modo de ser y comportamiento plúmbeo, de tal modo que aburría a sus amigos con sus bromas pesadas reiteradamente.

Estas estrategias de reparación de la comprensión pueden y deben ser programadas en las aulas de educación primaria y secundaria obligatoria, a través de procedimientos adecuados de enseñanza. Hurtar a los alumnos las prácticas pedagógicas que posibilitan su aprendizaje supone para muchos de ellos retrasar su competencia lectora general y su interés por la tarea.

\subsection{Criterios pedagógicos de desarrollo de esta estrategia}

Desde la perspectiva de una gestión global del trabajo con esta estrategia, es necesario contemplar los siguientes criterios pedagógicos:

- Programar el desarrollo de la estrategia, incluyendo las sesiones semanales en los que se trabajarán cada una de las actividades oportunas.

- Manejar textos auténticos variados y adaptados al nivel del alumnado: narraciones, comics, revistas, libros de texto, libros de consulta, etc.

- Utilizar como materiales la plantilla individual (figura 1) y el mural de la estrategia. El mural es la misma plantilla individual, pero ahora en formato cartulina para cuando se trabaja con todo el grupo-clase, mostrándola junto a la pizarra.

- Enseñar el vocabulario en un contexto real de lectura, no en actividades aisladas de rellenado de fichas.

- Modelar previamente el sentido y el uso de los componentes de la estrategia, mediante la reflexión en voz alta por parte del docente

- Crear oportunidades para que el alumnado, en trabajos de grupo, pueda hacer inferencias e hipótesis de significado sobre las palabras desconocidas, o las frases no comprendidas.

- Enseñar los prefijos, raíces y sufijos más comunes en español (ver figuras 4 y 5) 
- Instar a los alumnos a que trabajen sobre aquellas palabras desconocidas ya analizadas, anotando cómo han descubierto su significado, y pidiéndoles que las incluyan en una frase inventada (ver figura 6)

De acuerdo con la figura 2, los estudiantes van a tener la ocasión de trabajar sobre los siguientes componentes de la estrategia, aplicándolos en tareas de pequeños grupos a lecturas concretas, y llevando a cabo una autoevaluación de la destreza que muestran en su utilización:

1. Descompongo la palabra en partes para aclarar su significado

2. Vuelvo a leer y comprendo mejor

3. Continuo leyendo para descubrir otras pistas y comprender mejor

4. Compartiendo con mi compañero el significado

5. Busco el significado en el diccionario o en internet

\subsection{Fase de clarificación}

En esta fase, los estudiantes observan el discurrir del pensamiento en voz alta del profesor en dos sesiones, para descubrir el sentido y la aplicación práctica de esta estrategia.

- En la primera de ellas, el objetivo es descubrir a los lectores el significado de la estrategia y sus componentes.

- En la segunda, el profesor lee un texto previamente seleccionado, y modela en la práctica cómo utilizar y aplicar esos componentes. Para ello, descompone y analiza aquellas palabras que él considera son desconocidas para los estudiantes, esclareciendo su significado o releyendo y avanzando en la lectura, para buscar aquella/s pista/s que les precisen la comprensión del texto, y les permitan hipótesis sobre el significado.

He aquí un fragmento de esa primera sesión:

-Profesor:-(Tras colocar el mural de la estrategia junto a la pizarra).

-Hoy vamos a comenzar a trabajar la estrategia "Clarificamos el significado". A mi me ha pasado alguna vez que, al leer un libro, he tenido problemas cuando no he entendido el significado de algunas palabras o frases. ;Y cuando eso ocurre, es fatal!, uno termina por no comprender lo que ha leído.

-Pero yo he aprendido algunos trucos para poder solucionar ese problema y clarificar, o aclarar el significado Voy a enseñaros algunos de esos trucos que yo utilizo. Seguro que os van a dar muchas pistas sobre cómo descubrir el significado de esas palabras que nunca habéis oído y que son desconocidas para algunos de vosotros.

-¿qué significa "clarificar"

-Emilio: -Ya lo ha dicho usted, clarificar y aclarar es lo mismo, porque no sabemos lo que significa y nos aclara las palabras que no sabemos.

-Profesor:-iBien!. Así es, cuando yo os dije clarificar igual no entendiais lo que significaba; sin embargo, os dije a continuación... "o... aclarar". Después de "clarificar" os dije dos nuevas palabras: "o" y "aclarar". Seguro que Emilio ha entendido mejor "aclarar" que "clarificar”, ¿no?. 
VOCABULARIO: DESCUBRO SIGNIFICADO DE PALABRAS

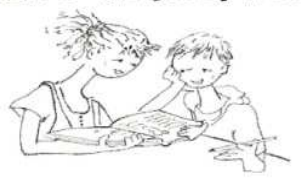

Alumno o atumna:

Fecha:

Líbro:

Autor o autora:

Ilustraciones: Editorial:

\begin{tabular}{|l|c|c|}
\hline PALABRA & $\begin{array}{c}\text { COMO FE DESCUBIERTO SU } \\
\text { SIGNIFICADO }\end{array}$ & $\begin{array}{c}\text { ESCRIBO UNA FRASE } \\
\text { CON ESA PALABRA }\end{array}$ \\
\hline & & \\
\hline & & \\
\hline & & \\
\hline & & \\
\hline & & \\
\hline & & \\
\hline & & \\
\hline & & \\
\hline & & \\
\hline & & \\
\hline & & \\
\hline
\end{tabular}

Opinión de mi profesor o profesora:

Figura 6: Plantilla para reflexionar sobre cómo se ha descubierto el significado de palabras 
-A mi también me hubiese ocurrido como a vosotros, que "aclarar" la hubiese entendido antes que "clarificar". El truco es que yo sé que la palabra "o", que va entre las otras dos, es una pista muy importante, a veces, para entender lo que significa la primera de ellas (clarificar), que era más complicada de entender.

- "Clarificar"... se entiende ahora mejor, ¿verdad?. Siempre que yo leo la vocal "o" entre dos palabras de un texto, posiblemente la palabra siguiente... "clarifica", o aclara, el significado de la que lleva detrás si no la he entendido iEse es uno de los trucos que tenéis que aprender!".

- "Además, yo también sé que clarificar, o aclarar" son dos palabras que significan lo mismo, son sinónimas, y detrás de la vocal "o", se suelen poner muchos sinónimos. Esta "o" me dio la pista para entender el significado de la palabra que iba delante: clarificar".

-Bien, sigamos. Los trucos o pistas para descubrir el significado están escritos aqui en el mural. Voy a pensar cómo yo los utilizo, para que aprendáis vosotros también.

-Emilio: -Yo ya sé un truco, que es buscar en el diccionario o en internet.

-Profesor: - -Ya!, ya veo que has leído el último componente de la estrategia que hay aqui en el mural; pero no siempre tenemos un diccionario a mano, o un ordenador.

-Emilio: $\quad$-iPero y si tengo un teléfono con conexión a internet! (risas)

-Profesor: - ¿Y qué ocurre cuando tampoco tienes el teléfono?... En ese caso, deberías aprender los otros trucos que hay en el mural.

-Los mejores trucos para averiguar el significado de palabras, ;y los que no se olvidan! son los que yo utilizo pensando y reflexionando sobre esas palabras, no los que nos ofrecen los ordenadores.

- Para mi es más fácil olvidar lo que significan las palabras si su significado lo he descubierto yo en un ordenador, o en un diccionario, porque cuando me dicen el significado ya no pienso en esas palabras, como lo haría utilizando trucos para adivinar lo que significan.

-Bien, sigo con lo que yo estaba pensando sobre cómo aprender el significado de esas palabras desconocidas. Aqui en el mural, el primer truco nos dice que para clarificar el significado de palabras desconocidas... las descomponemos en partes.

-¿Qué significa "des-componer"? (escribe en la pizarra la palabra ya segmentada). En esta palabra hay una parte de ella (la subraya), que es "componer" que yo la entiendo perfectamente... así, cuando compongo un rompecabezas, cojo sus piezas y las coloco, las ordeno y las organizo, componiendo una figura.

-Pero esa otra parte de la palabra "des" delante de componer significa algo, y posiblemente cambia el significado de "componer”, ¿no? ¿qué creéis vosotros?

Ana: ;Claro!, la parte "des" es hacer lo contrario de componer, o sea, deshacer, como hace mi hermana con mis cosas, las descompone, me las deshace.

Profesor: -iMuy bien! Es decir, componer es colocar todo en su sitio, hacer un puzle, y si ponemos delante el trozo "des", ahora ya cambia el significado a lo contrario, y ahora significa descolocar, deshacer.

- (escribiendo ahora la palabra "prefijo" en la pizarra).

-Yo sé que esos trozos que se colocan delante de una palabra, y que hacen que cambie su significado se llaman prefijos. Hay muchos prefijos (ya los iremos 
viendo). Y siempre que leamos y encontremos un prefijo como "des", nos fijaremos en él para ver cómo modifica el significado del otro trozo de palabra para que ésta signifique lo contrario: des-contento, des-acuerdo...

-Bien, otros trucos los encontraremos en los dos siguientes componentes de la estrategia, "volvemos a leer para comprender" y "continuamos la lectura para descubrir otras pistas y entenderlo mejor".

-A mi alguna vez me ha ocurrido que en una "re-lectura" de un texto que ya había leido antes, he encontrado pistas en las palabras ya leidas del propio texto, que me clarificaron una palabra desconocida que no habia comprendido.

-Por cierto, fijaros por favor en ese prefijo que os he dicho (re) que va delante de la palabra "lectura" ¿Verdad que leer y re-leer no significan lo mismo?. Ese prefijo ha cambiado el significado de leer. Sabemos lo que es leer, pero si delante lleva el prefijo "re" significa volver a leer.

Juan: - ¿Y cuáles son esas pistas de palabras del texto que clarifican lo que significa una desconocida?

Profesor: -Voy a escribiros en la pizarra una frase de un libro de la biblioteca del aula, el que trata sobre la historia de Federico, en el que hay una palabra desconocida para algunos de vosotros, y luego voy a hacer una relectura de esa frase, para descubrir una de esas pistas que me clarificarán lo que significa esa palabra desconocida.

- (escribe en la pizarra la siguiente frase, subrayando la palabra "suspicaz") "Federico es muy suspicaz, y sin embargo confía en los demás a veces"

- ¿Qué significa la palabra "suspicaz"?. Si yo hago una relectura del texto, ¡aqui está!, he encontrado la expresión formada por las palabras "sin embargo", que es la pista que necesitaba para hacer una hipótesis de lo que significa "suspicaz".

-Yo sé que, cuando los escritores incluyen esa expresión "sin embargo" después de una que no sé lo que significa, a veces me están diciendo que, en las palabras siguientes a "sin embargo" hay una pista de significado contrario de la palabra desconocida.

-O sea, después de "sin embargo", yo leo: “... confia en los demás a veces”. Por tanto, lo contrario de "confiar en los demás "es "desconfiar en los demás". iEso es!, Mi hipótesis inicial sobre lo que significa "suspicaz" es "desconfiado”, ¿no? ¡Ya entiendo la frase completa! A mi me gusta investigar el significado de palabras haciendo hipótesis a partir de pistas como ésta..

Javier: - ¿Y si no encuentras esas palabras que te clarifiquen lo que significa suspicaz?

Profesor:- Yo te aseguro que esa pista (sin embargo) abundan en los textos que leemos, y lo que hay que hacer es convertirse en detectives para encontrarlas ¿jugamos a ser detectives?...

-En todo caso, y como último recurso, existen los compañeros con los que intercambiar ideas u opiniones, investigando para descubrir lo que significan las palabras... jo incluso el diccionario o internet como decía Emilio! Pero eso ya como último recurso, cuando no hay posibilidades de descubrir lo que quiere decir la palabra. 
Es conveniente insistir en que el docente debe haber previamente seleccionado los textos necesarios para llevar a cabo tantas sesiones como sean necesarias, con el objetivo de ir descubriendo a los alumnos cada una de las pistas estratégicas que se han incluido en la sección 4.3. (Releer el texto o continuar leyendo para recuperar la comprensión), y reflexionar en voz alta sobre ellas en esas nuevas sesiones.

Para el desarrollo de la segunda sesión de esta fase de clarificación utilizamos el texto expositivo Cómo descubrió el hombre que el simio es primo suyo (10-14 años), de Juliette Nouel-Rénier. La actividad se lleva a cabo con todo el grupo. El profesor coloca junto a la pizarra el mural en formato cartulina de la estrategia (figura 2), con la instrucción de que siempre que un alumno descubra que se ha usado un componente, debe explicar al grupo cómo y por qué lo ha utilizado, y saldrá a la pizarra a poner una marca en el componente correspondiente.

En este fragmento reproducimos una sesión de trabajo de clarificación de los componentes de esta estrategia:

-Profesor:- (Se coloca el mural de la estrategia junto a la pizarra).

- Hoy vamos a trabajar los componentes de esta estrategia. Estar atentos a lo que yo leo y pienso en voz alta, y os reto a que descubráis qué componente de la estrategia, que están aqui escritos en el mural, he usado para clarificar el significado de una palabra. Quien lo descubra debe explicarlo al grupo y salir a la pizarra a marcar una cruz en el mural, exactamente en el componente que ha usado.

-(Tras leer el título del libro y la contraportada, mostrando la portada, los dibujos y las fotos, el profesor lee el título del capítulo que se va a leer y hace algunas preguntas para suscitar en los alumnos sus conocimientos previos sobre el tema)

-El título de este capitulo del libro es: "Primer chimpancé en Europa". Os leo: "El primer chimpancé vivo en desembarcar en Europa llega en 1630. Muere rápidamente y el cirujano holandés Nicolas Tulp, al que se confía el cadáver, declara que es un sátiro".

-Tengo que pararme a pensar en esta palabra. Tengo dudas de lo que significa "sátiro" ¿Alguno puede ayudarme?

(no respuesta)

-Releo otra vez lo leído y sigo con dudas. Voy a continuar leyendo para ver si encuentro alguna pista del significado de esta palabra... "...es decir, una criatura mitad hombre y mitad animal "... ;Ya está!. Hay una pista que me ha clarificado el significado de sátiro. Tras de esta palabra hay, entre comas, una expresión "es decir,..." y tras esta expresión lo que acabo de leeros: "una criatura mitad hombre y mitad animal”. ;Ya está! ;Eso es lo que significa sátiro!

-¿Qué componente he usado para clarificar el significado?

-Javier: - ¡Dos!, has releido y has seguido leyendo para clarificar esa palabra

-Profesor: - ¡Muy bien! ¿Y qué pista he encontrado para clarificar el significado de "sátiro"?

-Ana: -las palabras "es decir"

-Profesor: - iPerfecto! Esa expresión "es decir" nos introduce algo que va a explicar después lo que posiblemente no se entiende antes... Seguro que, cuando habláis, vosotros también usáis la expresión "es decir", para aclarar algo que habéis dicho antes, ¿no? 
-Fernando:-Sí, eso lo dicen mucho mis amigos y yo también, pero cuando leo a veces no me fijo y no me acuerdo que he leído... eso de "es decir".

-Profesor: -Yo cuando leo me voy fijando en esas pistas para comprender mejor. Sigo leyendo.. "También, a finales del siglo XVII, una curiosa criatura traída de Angola llega viva a Inglaterra, pero no sobrevive. El cirujano inglés Edward Tyson toma sus escalpelos para disecarla".

- Caray! Otra parada, porque esta palabra "escalpelos" es muy rara, y no entiendo su significado. Creo que lo mejor que voy a hacer es releer de nuevo para ver si encuentro alguna pista del significado de esta palabra...

-(tras la lectura, el profesor sigue reflexionando en voz alta).. El texto que acabo de leeros ahora dice que esa criatura había muerto y que el cirujano Edward Tyson tomó sus escalpelos.

-Eso quiere decir que los escalpelos es algo que usan los cirujanos para disecar a animales muertos y estudiarlos (vosotros sabéis lo que son animales disecados), porque Edward Tyson era cirujano, ¿no? ¿qué puede ser eso que usa?

-Ana: -El papá de un amigo mío es cirujano, se lo podemos preguntar.

-Javier: -No es necesario, en el texto el profesor ha leído que el cirujano usa el "escalpelo" para abrir y disecar a ese chimpancé. Y cuando lo disecaron seguro que lo abrieron, lo cortaron... ipuaf! a mí me da no sé qué pensarlo.

-Profesor: -Muy bien Javier, el significado de escalpelo es una especie de bisturí que usan los cirujanos para disecar o cortas tejidos corporales de un cadáver para estudiarlo. De todos modos, si Ana pregunta a su amigo seguro que nos traerá mañana una descripción más exacta del significado de esa palabra. ¿Qué componente he usado en esta estrategia para clarificar el significado?

-Javier: -Releer el texto para encontrar la pista de las palabras "cirujano" y "disecar" y ya sabemos eso de "escalpelo"

-Ana: -También si yo traigo el significado de esa palabra porque me lo dice el papá de mi amigo usamos el componente... aqui dice... "compartiendo con mis compañeros el significado"

(Se anotan las marcas respectivas en el mural de la estrategia).

\subsection{Fase de aplicación y perfeccionamiento}

Como con cualquier otra estrategia metacognitiva, en esta fase de aplicación y perfeccionamiento los alumnos son motivados a utilizar el conocimiento adquirido en las distintas sesiones de la fase de clarificación.

Para que los alumnos apliquen y perfeccionen su destreza en el cómo de esta estrategia, es importante promover aprendizaje cooperativo entre ellos, para así facilitarles la práctica y reflexión conjunta sobre el uso que hagan de los componentes trabajados. Siempre con la supervisión del docente y la puesta en común posterior con todo el grupo-clase, para fomentar el intercambio de ideas entre el alumnado.

Estas son las cuatro sesiones de trabajo que se proponen para esta fase:

En la primera sesión, los estudiantes se distribuyen en pequeños grupos de 3-4 alumnos. Se les entrega a cada alumno:

- Una copia de un texto corto (un folio de extensión), previamente elegido por el docente, en el que tengan la oportunidad de manejar algunos, o 
todos los componentes o acciones estratégicas a seguir para aclarar el significado de palabras o frases.

- La plantilla individual de la figura 3: Componentes de la estrategia Clarificamos el significado.

Como la tarea consiste en clarificar la comprensión del texto, reflexionando sobre el significado de palabras desconocidas que puedan encontrar, el docente se asegurará previamente de que ese texto contiene términos que puedan generar dificultades de comprensión. Dichas palabras deben ser motivo, bien de segmentación en prefijos, raíz y sufijos, o que tengan además que releer o avanzar en la lectura, compartir el significado entre ellos, o finalmente consultar en el diccionario o internet. En este sentido, antes de empezar a trabajar, es importante que el grupo tenga claro las acciones estratégicas a llevar a cabo, en función de lo que cada componente les pide que hagan. Para tal fin, un alumno del grupo leerá previamente en voz alta a sus compañeros los componentes de la plantilla individual, para repensar o repasar dichas acciones a seguir.

Durante el trabajo en común, cada alumno aportará al grupo la acción estratégica concreta que él ha usado, para descubrir el significado de la palabra o frase motivo de dificultad de comprensión en una frase concreta. Por tanto, es importante que cuando hagan sus intercambios, esas acciones como: descomponerla en partes para ver si alguna de ellas me da alguna pista de significado (prefijos, raíz, sufijo), pensando en otra palabra que se le parezca, o releyendo, etc. las expongan claramente al resto de compañeros. Para ello, el profesor escribirá en la pizarra las instrucciones de trabajo a seguir:

- Cada uno de vosotros leerá en voz baja el texto, subrayando la/s palabra/s que consideréis de dificil comprensión.

- Posteriormente, tomarás la decisión de qué componente es el que eliges para aclarar el significado perdido.

- Expondrás a continuación cómo has resuelto el problema de comprensión, clarificando el sentido de la palabra o frase del texto.

- Y finalmente, anotarás en tu plantilla individual una marca con el componente que has usado.

Una vez que el trabajo en pequeños grupos haya finalizado, se llevará a cabo una sesión de grupo-clase, en la que se dará la oportunidad al alumno que lo desee para justificar al resto de compañeros cómo ha clarificado la comprensión del texto cuando se ha encontrado una palabra desconocida:

- Exponiendo la acción estratégica y las pistas que ha utilizado para aclarar el significado.

- Revelando el significado de la parte del texto que le haya generado dudas de comprensión. 
En la segunda sesión, se invita a aquellos alumnos que lo deseen a encarnar el papel de un personaje ficticio, inventado por ellos que, jugando a investigar, "interprete" las acciones estratégicas a seguir para clarificar el significado de palabras desconocidas dentro de un texto. El grupo-clase se distribuirá en pequeños grupos (4-5 alumnos) y tomará decisiones sobre:

- El nombre del personaje que eligen. Normalmente los alumnos tienen imaginación suficiente para escoger el nombre de un personaje detectivesco. En caso necesario, se les pueden sugerir algunos (Simón el que descubre la comprensión, Clara la clarificadora, el detective frustrado que investiga el significado, Bienvenida la experta en la palabra desconocida...)

- El disfraz del personaje, con alguna indumentaria que le caracterice (unas gafas especiales, una lupa, unos prismáticos, etc.

- Textos cortos a trabajar en el grupo, que en total contengan al menos 34 palabras desconocidas (tantas como alumnos que forman el grupo).

- La elección del alumno que llevará a cabo la representación ante el grupo-clase.

- El contenido anotado, con las reflexiones que el personaje representará posteriormente ante el resto de alumnos de la clase.

- Los tiempos y espacios para ensayar la representación.

Se sugerirá a los lectores que dicha representación por parte del personaje elegido deberá observar al menos estas acciones:

- Lectura del texto elegido y modulación especial de la voz, con una pausa para expresar sorpresa, aturdimiento o confusión, cuando el personaje se encuentre con una de las palabras desconocidas.

- Expresión clara, recreada y divertida de las acciones estratégicas que tomará para descifrar el significado, pensando en voz alta acerca de si segmenta las palabras, o usa el contexto releyendo o avanzando en la lectura, etc.

Finalmente, se elegirá aquel grupo que haya llevado a cabo la mejor representación delante de toda la clase.

La tercera sesión, ahora de carácter individual, tiene como objetivo la reflexión personal sobre aquellas palabras de dificil comprensión que el alumno ha encontrado en un texto corto elegido por él mismo. Se aprovecharán los momentos de lectura independiente en la biblioteca de aula, para que los alumnos elijan el texto que consideren más conveniente para llevar a cabo el trabajo. Para tal fin, se entregará a cada uno de los estudiantes la plantilla de la figura 3 "Clarificamos el significado de palabras", en donde cada alumno anotará con una marca $(X)$, aquellos componentes de la estrategia que han utilizado para clarificar la comprensión.

La finalidad de la cuarta sesión es que los lectores practiquen la tarea de segmentar palabras desconocidas, para así elaborar después hipótesis de significado sobre ellas.

Se trata de una actividad de pequeños grupos, en la que se entrega a los alumnos las fotocopias que contienen la relación de prefijos y sufijos más importantes en español (figuras 4 y 5) y un texto que contenga palabras con posibilidad de ser segmentadas. Al final del trabajo, cada uno de los grupos compartirá con el resto de 
la clase cómo han usado esta estrategia, en su aplicación concreta a aquellas palabras que encontraron en el texto, y al significado de la frase en la que estaban ubicadas.

\subsection{Fase de autoevaluación}

Tras la ganancia obtenida en desarrollo estratégico y metacognitivo en las dos fases anteriores, tanto en capacidad de reflexión sobre el sentido de esta estrategia, como sobre los procesos de pensamiento a utilizar para manejar los componentes y clarificar el significado perdido durante la lectura, ahora es la oportunidad del alumno para autoevaluar individualmente su competencia en el manejo global de la estrategia, y dar así más pasos en la regulación de sus destrezas de comprensión.

Inicialmente, en la primera sesión, el profesor llevará a cabo una autoevaluación general de la competencia de los estudiantes, en una actividad de modelaje en la que, utilizando la estrategia de reflexión en voz alta, muestre a los alumnos cómo él evalúa varias de las plantillas individuales que se han trabajado en la fase de aplicación y perfeccionamiento de la estrategia. Frente al grupo-clase, el profesor colocará el mural junto a la pizarra, e irá anotando en él las marcas correspondientes a las veces que un componente haya sido usado en las distintas plantillas individuales seleccionadas previamente.

Finalmente, valorará positivamente el trabajo con algunos componentes (en función de su mayor uso) y pedirá a los alumnos que comenten las dificultades que hayan encontrado en la aplicación de esos otros componentes menos manejados, en función de los textos elegidos. Su valoración global deberá hacer hincapié en cómo subsanar las dificultades que plantean los estudiantes.

Tras esa valoración, el profesor sugerirá qué mejoras específicas en el manejo de los componentes de esta estrategia habría que contemplar en el futuro, para una mejor clarificación y control sobre los procesos de pensamiento en el tratamiento de las palabras desconocidas del texto.

En la segunda sesión, el profesor entregará a cada alumno las plantilla de la figuras 6 y 7, para que, en primer lugar, reflejen una autoevaluación de sus logros en el uso global y concreto de los componentes de esta estrategia y expongan qué acciones se proponen para mejorar su manejo en el futuro; $y$ en segundo, que anoten sus reflexiones acerca de cómo han descubierto el significado de determinadas palabras desconocidas.

La realidad de muchos centros escolares es que el currículo empaquetado que las editoriales ofrecen a los docentes de educación primaria y secundaria obligatoria para trabajar la comprensión lectora, con textos que incluyen algunas preguntas teóricamente diseñadas desde el enfoque cognitivo para mejorar la comprensión, "evalúan" básicamente la comprensión literal y, en muy pocos casos, algunos procesos estratégicos de comprensión. Estos procedimientos acaban convirtiéndose en tareas rutinarias de papel y lápiz, muy al estilo de las denostadas "fichas", en las que el alumno se limitaba a "rellenar" dichas preguntas.

Mientras los docentes no tengamos claro que estos materiales "hurtan" al lector de la utilización de su potencial estratégico, no podremos avanzar hacia nuevos procedimientos en donde se utilicen materiales auténticos de lectura, y se enseñe a los estudiantes de un modo directo y explícito cómo manejar destrezas cognitivas y metacognitivas de comprensión, para que aprendan a utilizarlas, tanto en trabajo cooperativo con sus pares, como individualmente. No debemos olvidar que comprender es una tarea que exige un lector activo, que movilice y aporte sus 
procesos de pensamiento para comprender. Y eso hay que aprenderlo a través de una instrucción directa y explícita en dichas destrezas, como una condición básica para un aprendizaje reflexivo y estratégico de la comprensión lectora, en la sociedad del siglo XXI. Una instrucción en estrategias lectoras debe contemplar dos objetivos básicos: por una parte, que el alumno sepa por qué, cómo y cuándo utilizar las estrategias adecuadas para mejorar su comprensión lectora; y por otra, que aprenda a controlar el proceso de lectura, para mejorar la comprensión.

En esta colaboración con Didáctica. Lengua y Literatura, hemos pretendido contribuir al impulso y promoción de la enseñanza directa de estrategias metacognitivas, con el desarrollo práctico de la estrategia clarificamos el significado. Nuestra experiencia nos demuestra que, cuando los lectores logran una cierta competencia en ella, están controlando el proceso de su propia comprensión, identificando los problemas que les van surgiendo en determinadas partes del texto, $y$ buscando aquellas pistas textuales que les descubran el significado perdido. Además, aprenden a enfrentarse a palabras desconocidas segmentándolas y reflexionando sobre sus prefijos, raíz o sufijos, como porciones semánticas, que les revelan el significado de las mismas y del texto en general.

\section{CONCLUSIONES}

Pasada la primera década del siglo XXI podemos concluir que, aunque desde la investigación y desde los datos que aporta el informe PISA se argumenta que existe una relación estrecha entre desarrollo metacognitivo y rendimiento en comprensión lectora, la experiencia nos muestra que no se da en las aulas una instrucción directa y explicita en estrategias que hagan consciente al lector de los procesos de pensamiento que deben movilizar para comprender textos, $i$. e. (esto es) estrategias metacognitivas.

En definitiva, señalar que si la escuela debe ofrecer a los estudiantes la oportunidad de que aprendan a comprender, la utilización de procesos de reflexión sobre cómo buscar significado en un texto, constituye una marca de excelencia en la mejora de la competencia lectora que deben ser enseñados de un modo directo y explícito en nuestras aulas de educación primaria y secundaria obligatoria.

\section{BIBLIOGRAFÍA}

ALONSO, J. y MATEOS, M.M. (1985) Comprensión lectora: Modelos, entrenamiento y evaluación. En Infancia y Aprendizaje, (31-32), 5-19.

BAKER, L., \& BROWN, A.L. (1984a) Metacognitive skills and reading. En P.D. PEARSON, M. KAMIL, R. Barr, \& P. Mosenthal (eds). Handbook of Research in Reading, 353-395. New York: Logman.

BAKER, L. \& BROWN, A.L. (1984b) Cognitive monitoring in reading. En J. FLOOD (ed) Understanding Reading Comprehension , 21-44. Newark, DE. International Reading Association. 


\section{REFLEXIONO SOBRE COMO CLARIFICO EL SIGNIFICADO DE LAS PALABRAS DEL TEXTO}

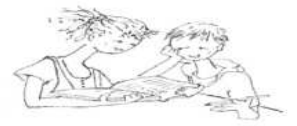

Alumno o alumna: ...........

Fecha : 2.2. $10.7 / \% 2007$

1.-Marca con una $X$ la cuadrícula de aquello que haces muy bien cuando clarificas el significado de las palabras del texto mientras lees; y con una + la cuadrícula que indique aquello que no haces bien, y que deberias hacer mejor.

$f$ Descompongo las palabras en partes para comprenderlas mejor

Xuelvo a leer para buscar pistas que me clarifiquen el significado

X Continúo la lectura para seguir buscando otras pistas del significado

Pregunto a mis compañeros lo que significan las palabras

Uso el diccionario o internet para averiguar el significado

2. ¿Por qué crees que es importante utitizar esta estrategía para comprender la lectura?

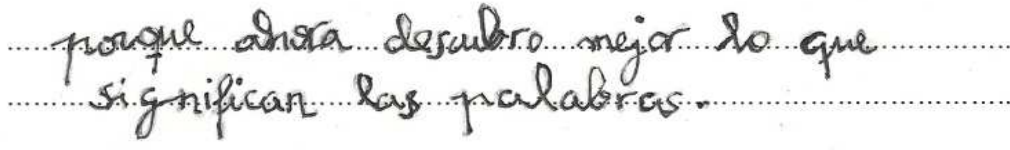

3. - Escribe aquelto en to que deberias mejorar para utulizar esta estrategia

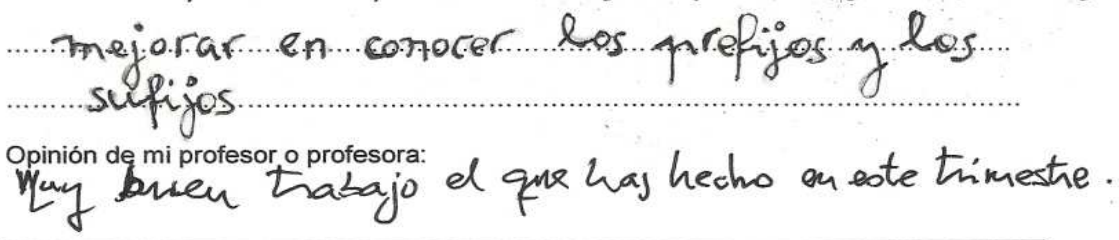

Figura 7: Plantilla de autoevaluación uso de componentes de la estrategia. 
BROWN, A.L. (1980). Metacognitive development and reading. En R.J. SPIRO, B. C. BRUCE \& W.F. BREWER (eds). Theoretical Issues in Reading Comprehension, 458-482. New Jersey: Erlbaum.

BROWN, A.L. (1978). Knowing when, where and how to remember: A problem of metacognition. En R.GLASER (eds) Advances in Instructional Psychology, 7165. Hillsdale. JN: Erlbaum.

BROWN, A. L.(1987). Metacognition, executive control, self-regulation and other more mysterious mechanisms. En E. WEINERT y R. KLUWE (eds). Metacognition, Motivation and Understanding, 65-116. Mahwah, New Jersey:Erlbaum.

BROWN, A.L., PALINSCAR, A.S., ARMBRUSTER, B.B. (2006) Instruction comprehension-fostering activities in interactive learning situation. En RUDDEL \& UNRAU(Eds) Theoretical Models and Processes of Reading.(pp.780-809). International Reading Association.

CALERO, A. (2011). Cómo mejorar la comprensión lectora. Estrategias para lograr lectores competentes. Wolters Kluwer. Madrid.

COMISIÓN NACIONAL DE LECTURA (2000). Report of the National Reading Panel: Teaching children how to read, Oficina de Publicaciones del Gobierno de Estados Unidos, Washington DC.

DUFFY, G.G: (2002). The case for direct explanation of strategies. En C.C. BLOCK \& M. PRESSLEY (Eds), Comprehension instruction (pp. 28-41). New York: Guilford.

DUKE, N.K., Pearson, P.D., Strachan, S.L. \& Bilman, A.K. (2011) Essential elements of fostering and teaching reading comprehension. En What Research Has to Say about Reading Instruction (4 ${ }^{\text {th }}$ edition), 51-93. International Reading Association.

FLAVELL, J.H. (1976) Metacognitive aspects of problem solving. En L.B. Resnick (ed). The Nature of Intelligence, 231-235. Hillsdale. NJ: Erlbaum.

FLAVELL, J.H. (1979) Metacognition and cognitive monitoring: A new era of cognitive development inquiry. En American Psychologist, (34), 906-911.

FLAVELL, J.H. (1993) El desarrollo cognitivo. Visor. Madrid.

INSTITUTO DE EVALUACIÓN (2010). La lectura en PISA. Secretaría de Estado de Educación y Formación Profesional. Ministerio de Educación. Madrid.

ISRAEL, Susan E. (2007). Using metacognitive assessment to create individualized reading instruction.Newark DE. International Reading Association.

JACOBS, J.E, \& PARIS, S.G. (1987). Children's metacognition about reading: Issues, definitions measurement and instruction. En Educational Psychologist, (22), 255-278.

JARAMILLO, A.; MONTAÑA, G; ROJAS, L. (2006). Detección de errores en el proceso metacognitivo de monitoreo de la comprensión lectora en niños. En Revista Latinoamericana de Ciencias Sociales, 4,(2). 
KELLEY, M.J. \& Clausen-Grace, N. (2007) Comprehension shouldn't be silent. International Reading Association. Newark.

McCUTCHEN, D. \& Logan, B. (2011). Inside word learning: Children's strategic use of morphological information to infer word meaning. En Reading Research Quarterly, 46(4). Pp.334-349. International Reading Association.

MEC (2007) Orden ECI/221/2007 de 12 de julio, por la que se establece el currículo y se regula la ordenación de la Educación Primaria. En Web http://www.boe.es/boe/dias/2007/07/20/pdfs/A31487-31566.pdf

MEC(2007) Orden ECI 2220/2007 de 12 de julio, por la que se establece el currículo y se regula la ordenación de Educación Secundaria Obligatoria. En Web http://www.boe.es/boe/dias/2007/07/21/pdfs/A31680-31828.pdf

PRESSLEY, M., WHARTON, R.,MISTRETTA-HAMPSTON, J. \& ECHEVARRÍA, M. (1998) The nature of literacy instruction in ten grade $-4 / 5$ classrooms in upstate New York. En Scientific Studies of Reading,(2), 159-194.

VIDAL-ABARCA, E., MAÑÁ, A., GIL, L. (2010). Individual differences for selfregulating task-oriented Reading activities. En Journal of Educational Psychology, 102 (4), 817-826.

WYSOCKI, K. \& JENKINS, J.R, (1987). Deriving word meaning through morphological generalization. En Reading Research Quarterly, 22(1), pp. 66-81

ZWIERS, J. (2010). Building reading. Comprehension habits. International Reading Association. 